\title{
Critical success factors model developing for sustainable Kaizen implementation in manufac- turing industry in Ethiopia
}

\author{
Haftu Hailu ${ }^{a, b^{*}}$, Abdelkadir Kedir ${ }^{b}$, Getachew Bassa ${ }^{b}$ and Kassu Jilcha ${ }^{c}$
}

${ }^{a}$ Public Service and Human Resource Development Ministry: Ethiopia Kaizen Institute, Addis ababa, Ethiopia

${ }^{b}$ Ethiopian Institute of Technology Mekelle, Mekelle University, Tigray, Ethiopia

${ }^{c}$ Addis Ababa University, Addis Ababa Institute of Technology, Addis Ababa, Ethiopia

CH R O I C LE A B T T A C T

Article history:

Received: July 24, 2017

Received in revised format: $\mathrm{Au}-$ gust 6, 2017

Accepted: August 24, 2017

Available online:

August 24, 2017

Keywords:

Kaizen

Critical Success Factor

Success Indicator

Factor analysis

Peacock

\begin{abstract}
The purpose of the research is to identify critical success factors and model developing for sustaining kaizen implementation. Peacock shoe is one of the manufacturing industries in Ethiopia facing challenges on sustaining. The methodology followed is factor analysis and empirically testing hypothesis. A database was designed using SPSS version 20. The survey was validated using statistical validation using the Cronbach alpha index; the result is 0.908 . The KMO index value was obtained for the 32 items and had a value of 0.642 with Bartlett's Test of Sphericity Approx. ChiSquare 4503.007, degree of freedom 496 and significance value 0.000 . A factor analysis by principal components and varimax rotation was applied for finding the critical success factors. Finding designates that 32 items were merged into eight critical success factors. All the eight factors together explain for $76.941 \%$ of the variance. Multiple regression model analysis has indicated that some of the critical success factors had relationship with success indicators. Due to constraint of time, the researcher focused only at peacock shoe manufacturing industry. Other limitation also includes the absence of any local research that shows the critical success factors at the moment.
\end{abstract}

\section{Introduction}

Now a days manufacturing industries are facing challenges due to the fastest changes of pace in technology and market demands. In recent years, manufacturing industries have also experienced unprecedented degrees of change in management, process technology, customer expectations, supplier attitudes and competitive behavior. This elaborates that industries which have manufacturing systems, with great trustworthiness, have implemented superlative manufacturing approaches such as Kaizen philosophy. Change is now a permanent feature of the business environment and organizations, which adapt to this new environment, are more likely to gain a significant competitive advantage (Mfowabo, 2006). In 1970 Japan's export was better than its import, the main reason for this achievement was Japan's manufacturing industries successfully implemented kaizen (Bisht, 2013) following the success of Japan's firms, Japan takes initiative to support Africa under Yokohama action plan. Ethiopia has experienced

* Corresponding author. Tel.: +251-912-19-27-41

E-mail address: hhea192741@gmail.com (H. Hailu) 
a fast economic growth in recent years with the annual GDP growth rate average $11 \%$. The industry sector also shows growth at an alarming rate for the past four years in the local share of production quantity ranging from $10.30 \%$ to $14.3 \%$. The GDP share of the manufacturing sector ranging from $4.4 \%$ to $4.6 \%$ which is less than those of other countries with the similar income level (MOI: GTP II, 2015).

In Ethiopia manufacturing sector, the slow development of the private sector, the poor quality control, and the low productivity have been major obstacles for promoting exports and domestic and foreign investments. For sustainable economic growth and poverty reduction in Ethiopia, it is essential to develop the private sector or to strengthen the competitiveness of its economy through improving the quality control and productivity. Therefore, Peacock shoes manufacturing industry is one of the export oriented industry which have implemented the Kaizen philosophy to enhance its competitiveness. At the time of implementation, company was achieving substantial tangible and intangible improvements with attractive physical changes. However, the company is facing challenges on sustaining Kaizen implementation and substantial improvements. This research addresses on identifying critical success factors that enables to sustain the implementation. The research is done by listing factors that affect Kaizen implementation from previous researchers reported from different companies and countries. According to (García et al., 2013). Critical success factor (CSFs) were proposed by Daniel in 1961, and this idea was popularized by Rock arts in 1979. Study of information systems, over the past two decades has demonstrated that the CSFs method has been widely adopted and used in a variety of fields of study to determine the most critical factors influencing enterprise success. However, there is no one particular definition of success, as the definition of success is different from one person to another, depending on the perspective of the person who defines it.

There are different definitions for CSF. According to Rockmart, critical success factors are defined as inadequate number of duties and responsibilities which enables to confirm successful competitive performance for any manufacturing industry are critical success factors. Leidecker's definition of critical success factors is those items that, when appropriately standardized, maintained, improved, sustained or managed, can have a substantial impact on the success of an organization rival in particular industry (Leidecker \& Bruno, 1984). According to Boynton and Zmud (1984), critical success factors are defined as those insufficient items which confirms success for any manufacturing industry. The researcher also defines critical success factors as those few or many key main activities (depends on the wing of the industry) which are driving forces for successful completion of any strategy by achieving qualitative and quantitative results. Based on this, When manufacturing industries want to improve their existing gaps on implementation or working processes, they need to focus on some specific areas in order to identify critical success factors. This also allowed them to see their capability to meet any requirements related to critical success factors. Furthermore, the CSFs concept is the most important for overall organizational objectives, mission and strategies. The researcher wants to ask an important question based on the above CSF concept: what companies are doing in other countries for successful implementation of their continuous improvement activities? And what should peacock manufacturing industry do to sustain kaizen implementation activities? Regarding to react the questions shown above, the researcher found in a literature review that there are adequate components that contribute to the successful implementation of Kaizen. 20 authors and 41 factors sorted according to their numbers of references. Some factors that were cited only once, which are associated with effective internal processes, $5 \mathrm{~s}$ implementation (Leidecker \& Bruno, 1984) workplace safety (Farris, 2003), focus on customers (Romero et al., 2009), application of methodologies to understand customer's voice, resistance to change, consistent approach to improvement activities and development of structures to stop the bugs, make operating practices, establishment of long-term goals, and shaping a learning organization and focus on development of critical processes and quality management systems (Landa, 2009). Other factors that were cited at least two times from literature are: commitment and motivation of staff (Tapias et al., 2010); support from senior management (Cooney \& Sohal, 2004); allocated resources (time, economic, spaces) (Bisgaard, 2007); leadership (Leidecker \& Bruno, 1984); developing a culture of continuous improvement 
(Prajogo \& Sohal, 2004); set goals for improvement programs (Jørgensen et al., 2004); using an appropriate methodology (Bisgaard, 2007); standardization and process measurement (Farris, 2003); organization of support teams, presence of a facilitator to support the program (Prajogo \& Sohal, 2004); interdepartmental communication (Tapias et al., 2010); differences between the focus of improvement and the existing culture, Employee attitude (Landa, 2009); Interdepartmental cooperation, follow the PDCA cycle (Bisgaard, 2007); training and education (García et al., 2013); heterogeneity of improvement teams , assessment system (Readman, 2003); skills and experience,; establish policies, objectives and structure (Tapias et al., 2010); clarify goals and common ideas, documentation and evaluation; workers integration and award; customer focus (García et al., 2013). Besides, many view Kaizen as a long term journey, Kaizen champions, financial capabilities, involve and value employees at all levels of the organization, problem solving by involving people, realistic timescales for changes, standardization, views and understand kaizen as a philosophy rather than another strategy are factors affecting the successful kaizen implementation (Alaskari et al., 2012).

The researcher criticizes different authors for only identifying critical factors; they are not developing any model which enables sustainable Kaizen implementation. Even Vermaak (2008) focused only on people and process. These two only did not enable for successful completion. Rather during implementation people should solve problems faced on each process by creating new improvement ideas in good management. Based on this reason this research gave high focus for the 4p's of people, philosophy, process and problem solving for successful completion and sustainable kaizen implementation.

There have been several studies on the reasons on why companies implement Kaizen, the benefits to be derived from Kaizen, as well as the tools and techniques of Kaizen have been well researched and documented. However, little is known about the reasons for failed kaizen implementation, how to avoid the pitfalls and what to do to ensure the success of kaizen in Ethiopia manufacturing context. It is clear that despite the popularity and growth Kaizen philosophy takes in Ethiopia. Most of the manufacturing industries are not successful and even the few successful manufacturing industries like peacock are backfiring and suffering a lot of challenges on sustaining the Kaizen implementation and substantial improvements. Most of the problems are internal like high machine breakdowns, high concentration of wastes, lower employee involvement, high defects and reworks are few due mentioned. With this in mind, the researcher has, therefore, focused on Peacock shoes manufacturing with a view to determine the questions: what are the critical success factors for sustainable Kaizen implementation in Peacock manufacturing industry? What are the main critical success factors of kaizen reported in the previous researchers? Which model should be used at peacock? What kind of model was developed for sustainable kaizen implementation? Therefore, the researcher believed that identifying and developing model of few critical success factors in the company would lead them on sustaining kaizen activities, competitive globally and leading line of existing companies in the country.

\section{Experimental Procedure}

The research was done using different materials and methods. 32 main items affecting the implementation, 19 success indicators, theoretical model and 10 hypotheses are used on the research. Since the population size of the company is known, so to decide the required sample size, the following proven formula was used as shown in Eq. (1) (Krejcie \& Morgan, 1970).

$$
S=x^{2} N P(1-P) /\left(d^{2}(N-1)+x^{2} P(1-P) .\right.
$$

where, $\mathrm{s}=$ required sample size; $=$ the table value of chi-square for $1 \mathrm{DOF}$ at the desired confidence level (3.841); $\mathrm{N}=$ the population size (for the case of peacock $\mathrm{N}=256$ ); $\mathrm{P}=$ the population proportion (assumed to be 0.50 since this would provide the maximum sample size); $d=$ the degree of accuracy 
expressed as a proportion (0.05). After applying the survey, a database was designed using Statistical Package for Social Sciences, version 20. The statistical analysis included several phases.

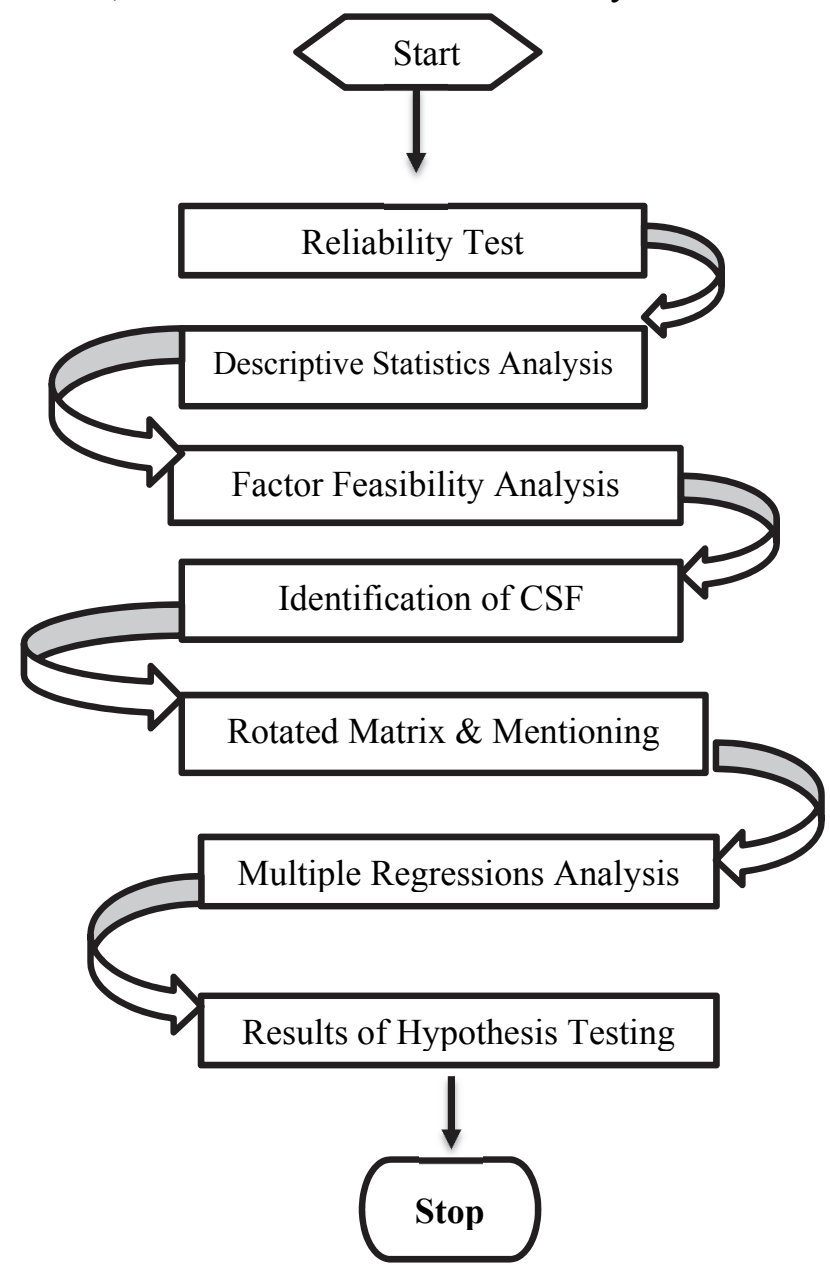

Fig.1. Flow chart of methodology

The potential influence of critical success factors on success indicators are described in Fig. 2. The following hypotheses were formulated for each linkage. These are theories that will be empirically tested. The researcher tried to modify, propose the theoretical model and go through (Vermaak, 2008). H1: Providing comprehensive training and education to all levels of the company starting from shopfloor employees to top managements will result in increased employees performance, customer satisfaction and decreasing manufacturing costs.

H2: Having ownership towards the philosophy will result in increased employees performance, customer satisfaction and decreased manufacturing cost.

H3: when employees working in team will result in increased employee's performance, customer satisfaction and decreased manufacturing cost.

H4: Having effective vertical and horizontal communication in providing frame work of strategic improvement plan will result in increased employees performance, customer satisfaction and decreasing in manufacturing cost.

H5: All levels of company employee's participation in the Kaizen implementation will result in increased employees performance, customer satisfaction and decreasing in manufacturing cost.

H6: Using process control and improvement techniques will result in increased employee's performance, customer satisfaction and decreasing manufacturing cost. 
H7: Continual evaluation of the implementation and the performance of all levels of employees will result in increased employee's performance, customer satisfaction and decreased manufacturing cost. H8: Establishing recognition and reward system in the company will result in increased employee's performance, customer satisfaction and decreased manufacturing cost.

H9: Knowledgeable and committed effective Kaizen leadership will result in increased employee's performance, customer satisfaction and decreased manufacturing cost.

H10: Employee's attitude will result in increased employee's performance, customer satisfaction and decreased manufacturing cost.

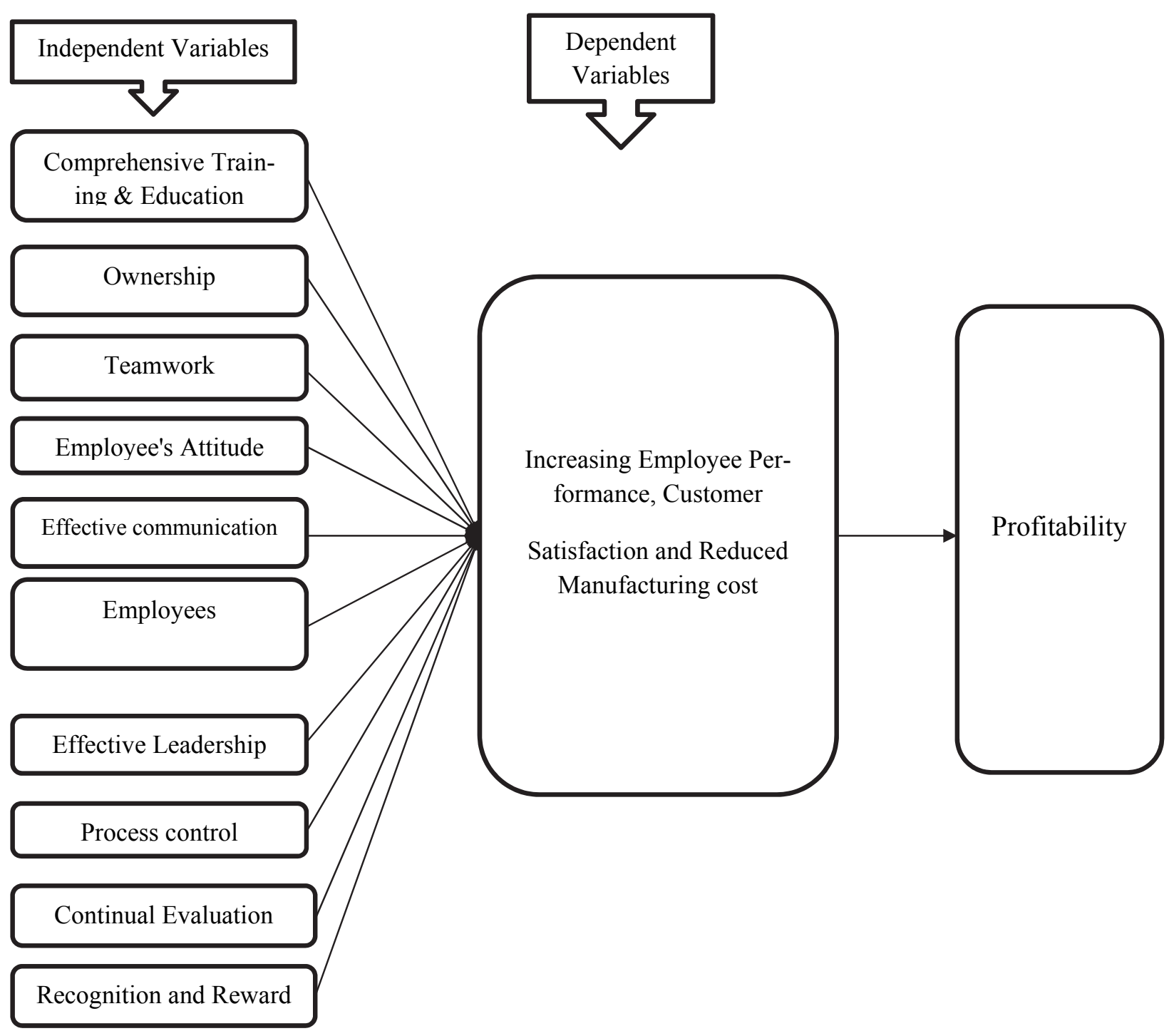

Fig. 2. Conceptual model before emperically testing

\section{Results and Discussion}

\subsection{Statistical Analysis of Questionnaire}

\subsubsection{Reliability Test Result}

Different authors accept different values of this test in order to achieve internal reliability, according to Asedesach (2014), the minimum required value is 0.7 . The CAI was obtained for the 32 initial items 
that is 0.908 . Different authors agree that removing some items from the questionnaire results on improving the CAI value (Bisgaard, 2007). The researcher found that not important eliminating the variables since the existing variables internal consistency was maintained. The Cronbach's coefficient alpha was calculated for each item of the questionnaire with minimum 0.901, maximum 0.913 and the 32 items as a whole scored CAI value 0.908 that is excellent. Therefore, based on the test, the results for the items are reliable and acceptable.

\subsubsection{Descriptive Statistics Analysis}

Descriptive analysis is done first to know the level of importance of factors. With 5 point Likert scales, the interval for breaking range in measuring each variable is calculated by Eq. (2):

$$
R=(N-1) / N
$$

where $R$ is the interval for breaking the range; $N$ is the maximum applied Likert scale. According to the analysis, 32 items recorded minimum 3.94 and maximum 4.68 that is 31 items falling on the interval breaking range 4.20 to 5.00 most important items and one item on the interval breaking range 3.40 to 4.19 high important. This result is excellent and shows that all the respondents agree on the importance of all variables for successful Kaizen implementation.

\subsubsection{Factor Feasibility Analysis}

The following criteria are used to assess and describe the sampling adequacy: $0.90=$ excellent; $0.80=$ very good; $0.70=$ good; $0.60=$ fair; $0.50=$ poor and below $0.50=$ unacceptable. If $\mathrm{KMOs}<0.5$, it is a good idea not to do factor analysis. The Bartlett's Test of Sphericity is the test for null hypothesis that the correlation matrix has an identity. Very small values of significance (below 0.05) indicate a high probability that there are significant relationships between the variables, whereas higher values (above 0.05 ) indicate the data is inappropriate for factor analysis.

\section{Table 1}

KMO and Bartlett's Test Measure of Sampling Adequacy as a whole

\begin{tabular}{crc}
\hline \multicolumn{3}{c}{ KMO and Bartlett's Test } \\
\hline Kaiser-Meyer-Olkin Measure of Sampling Adequacy. & 0.642 \\
\hline & Approx. Chi-Square & 4503.007 \\
Bartlett's Test of Sphericity & Df & 496 \\
& Sig. & 0.000 \\
\hline
\end{tabular}

Table 1 illustrates the KMO index value obtained for the 32 items and had a value of 0.642 which is above 0.6 average and acceptable. The Bartlett's Sphericity test gave a chi-square value of 4503.007 with 496 degrees of freedom that represents a $p$ - value (significance) of 0.000 which is less than a $95 \%$ level of Significance, $=0.05$. The determinant value of the correlation matrix was estimated in 0.000 . With this feasibility indexes, the conclusion was that the factor analysis could be applied. Factor analysis is a statistical technique that is used to identify a relatively small number of factors in order to represent the relationship among a set of interrelated variables (Blanche et al., 2006). The researcher applied three steps for factor analysis: Computing inter correlations between variables (correlation matrix); Extracting initial factors, and Rotate in the factors to obtain a clearer picture of the factor content. The researcher tried to know the inter correlation between variables. The result illustrates that after extraction, the 32 items have KMO index value: 1 item score above 0.9 Excellent, 10 items score above 0.8 Very good, 15 items score above 0.7 Good, 5 items score above 0.6 Faire, 1 item score above 0.5 poor but acceptable. These items are with allowable SAM value. In factor analysis, only those factors with an eigenvalue greater than unity were considered], and only eight factors meet that requirement, which together accounts for $76.941 \%$ of all eigenvalues. Therefore, eigenvalue of component 
$1,2,3,4,5,6,7,8$ are $9.206,3.472,3.141,2.748,1.940,1.624,1.260,1.230$ respectively. Table 3.2.below describes the total variance explained extraction sums of squared loadings. The researcher therefore wants the items to be loading properly on the factors. Different authors agreed that, the greater the loading, the more the variable is a pure measure of the factor. Loadings in excess of: 0.71 are considered excellent, 0.63 are considered very good, 0.55 are considered good, 0.45 are considered fair, and 0.32 are considered poor. Choice of the cutoff for size of loading to be interpreted is a matter of researcher preference]. Eight factors have been extracted based on their eigenvalues greater than one. Besides, each factor is constituted of all those variables that have factor loadings greater than the maximum limit 0.7 as shown in Table 2 which is excellent. 32 variables were clubbed into eight factors.

Table 2

Total variance explained extraction sums of squared loadings

\begin{tabular}{lccc}
\hline Component & \multicolumn{3}{c}{ Extraction Sum of Square Loading } \\
\cline { 2 - 4 } & Total & \%o of Variance & Cumulative \% \\
\hline 1 & 9.206 & 28.768 & 28.768 \\
2 & 3.472 & 10.850 & 39.618 \\
3 & 3.141 & 9.817 & 49.434 \\
4 & 2.748 & 8.589 & 58.023 \\
5 & 1.940 & 6.063 & 64.086 \\
6 & 1.624 & 5.075 & 69.160 \\
7 & 1.260 & 3.938 & 73.098 \\
8 & 1.230 & 3.843 & $\mathbf{7 6 . 9 4 1}$ \\
\hline
\end{tabular}

Table 2 illustrates, the eight extracted factors explained $76.941 \%$ of the variability factors for successful Kaizen implementation. This explains above three-fourth of the variability.

The researcher tried to use the scree plot for showing the relationship between eigenvalues and factors: Fig. 3 illustrates the scree plot graphs the eigenvalues against each factor. We can see that from the graph that after factor eight there is a sharp change in the curvature of the scree plot. This shows that after factor eight the total variance accounts for smaller and smaller amounts. Factors are interpreted through their factor loadings.

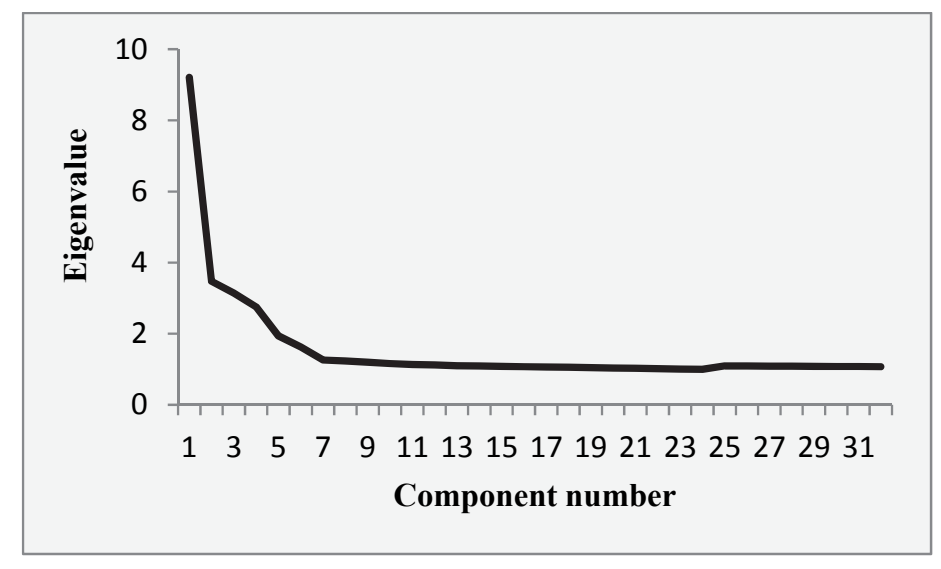

\subsubsection{Identification of Critical Factors}

Fig. 3. Scree plot

The researcher here wants rotating the factors to obtain a clearer picture of the factor content. The factor matrix was than rotated to simple structure by means of Varimax Rotation with Kaiser Normalization (Vermaak, 2008). 
Table 3 illustrates the total variance explained - rotation sum of square loadings after rotation. Thus, after rotation, Factor 1 accounts for $16.056 \%$ of the variance; Factor 2 accounts for $10.286 \%$ of the variance; Factor 3 accounts for $9.996 \%$ of the variance; Factor 4 accounts for $9.157 \%$ of the variance; Factor 5 accounts for $8.525 \%$ of the variance; Factor 6 accounts for $8.253 \%$ of the variances; Factor 7 accounts for $7.369 \%$ of the variance; Factor 8 accounts for $7.298 \%$. All the eight factors together explain for $76.941 \%$ of the variance in successful kaizen implementation.

Table 3

Total variance explained - rotation sum of square loadings

\begin{tabular}{lccc}
\hline Factors & \multicolumn{3}{c}{ Rotation Sums of Squared Loadings } \\
\cline { 2 - 4 } & Total & \% of Variance & Cumulative \% \\
\hline 1 & 5.138 & 16.056 & 16.056 \\
2 & 3.291 & 10.286 & 26.342 \\
3 & 3.199 & 9.996 & 36.338 \\
4 & 2.930 & 9.157 & 45.496 \\
5 & 2.728 & 8.525 & 54.021 \\
6 & 2.641 & 8.253 & 62.274 \\
7 & 2.358 & 7.369 & 69.643 \\
8 & 2.335 & 7.298 & $\mathbf{7 6 . 9 4 1}$ \\
\hline
\end{tabular}

\subsubsection{Rotated Matrix and Mentioning CSF}

The researcher mentions critical success factors after examines the rotated factor matrix as shown in table 4 below. This table illustrates the rotated factor matrix correlation of the variables with each of the extracted factors. Usually, each of the variables is highly loaded in one factor and less loaded towards to the other factors. To identify the variables, included in each factor, the variable with the value maximum in each row is selected to be part of the respective factor. The values greater than and equal to 0.494 have been highlighted in each of the rows to group the 32 variables in to 8 critical factors.

\section{Table 4}

After rotated matrix mentioning eight critical success factors

\begin{tabular}{|c|c|c|c|}
\hline Factor & Code & Factor load & Name of the factor \\
\hline \multirow[t]{6}{*}{1.} & PII23 & 0.628 & \multirow{6}{*}{ Preparation (Ownership; Training \& Education) $16.056 \%$} \\
\hline & $\mathrm{PII} 24$ & 0.795 & \\
\hline & PII27 & 0.788 & \\
\hline & PII29 & 0.715 & \\
\hline & PII31 & 0.576 & \\
\hline & PII32 & 0.795 & \\
\hline \multirow[t]{4}{*}{2.} & PII2 & 0.740 & \multirow{4}{*}{ Process control \& improvement $10.286 \%$} \\
\hline & PII3 & 0.771 & \\
\hline & PII4 & 0.646 & \\
\hline & PII8 & 0.549 & \\
\hline \multirow[t]{4}{*}{3.} & PII7 & 0.666 & \multirow{4}{*}{ Planning (Effective communication) $9.996 \%$} \\
\hline & PII11 & 0.854 & \\
\hline & PII12 & 0.751 & \\
\hline & $\mathrm{PII} 22$ & 0.600 & \\
\hline \multirow[t]{4}{*}{4.} & PII6 & 0.885 & \multirow{4}{*}{ Implementation (teamwork and Employee participation) $9.157 \%$} \\
\hline & PII13 & 0.901 & \\
\hline & PII16 & 0.538 & \\
\hline & PII20 & 0.565 & \\
\hline \multirow[t]{5}{*}{5.} & PII10 & 0.925 & \multirow{5}{*}{ Effective leadership $8.525 \%$} \\
\hline & PII14 & 0.494 & \\
\hline & PII15 & 0.585 & \\
\hline & PII18 & 0.624 & \\
\hline & PII19 & 0.541 & \\
\hline \multirow[t]{3}{*}{6.} & PII5 & 0.794 & \multirow[t]{3}{*}{ Continual evaluation $8.253 \%$} \\
\hline & PII9 & 0.579 & \\
\hline & PII30 & 0.799 & \\
\hline \multirow[t]{3}{*}{7.} & PII1 & 0.761 & \multirow[t]{3}{*}{ Recognition \& rewarding $7.369 \%$} \\
\hline & PII17 & 0.636 & \\
\hline & PII 25 & 0.595 & \\
\hline \multirow[t]{3}{*}{8.} & PII21 & 0.648 & \multirow{3}{*}{ Employee's attitude $7.298 \%$} \\
\hline & PII26 & 0.577 & \\
\hline & PII28 & 0.589 & \\
\hline
\end{tabular}


Six items loaded on Factor 1, four items on Factor 2, four items on Factor 3, four items on Factor 4, five items on Factor 5, three items on Factor 6, three items on Factor 7, three items on Factor 8. All factors consist of at least three items, which is in line with Thurstone's recommendation of at least three variables per factor for exploratory analysis.

\subsubsection{Multiple Regression Analysis}

In order to empirically evaluate the various relationships in success indicators and critical success factors, a multiple regression analyses is needed to be applied. As such the influence of each of the eight critical success factors or independent variables on each of the three success indicators or dependent variables needed to be assessed. Multiple regression analysis is one of the most commonly used multivariate procedures and is used to build models for predicting scores on one variable, the dependent variable, from scores on a number of other variables, the independent variables (Terre et al., 2006). The researcher tried to predict successful kaizen implementation in terms of staff performance, customer satisfaction and manufacturing cost reduction variable from independent variables of preparation (ownership, education \& training), process control and improvement, planning (effective communication), implementation (employee's participation and teamwork), effective leadership, continual evaluation, recognition and reward, employee's attitude.

Table 5

Summary result from regression model (Customer satisfaction)

\begin{tabular}{lcccc}
\hline Code & R square & Coefficients (Beta) & t & Sig \\
\hline PII29 & 0.244 & .385 & 3.815 & 0.000 \\
PII24 & 0.244 & .327 & 2.491 & 0.014 \\
PII12 & 0.194 & 0.214 & 2.031 & 0.044 \\
PII11 & 0.194 & -0.353 & -3.274 & 0.001 \\
PII22 & 0.194 & 0.282 & 2.967 & 0.004 \\
PII10 & 0.304 & -0.234 & -2.721 & 0.007 \\
PII14 & 0.304 & 0.295 & 3.294 & 0.001 \\
PII18 & 0.304 & 0.432 & 4.545 & 0.000 \\
PII19 & 0.304 & -0.238 & -3.068 & 0.003 \\
PII25 & 0.106 & 0.257 & 2.367 & 0.019 \\
PII28 & 0.153 & .410 & 4.581 & 0.000 \\
\hline
\end{tabular}

Note: Significance value of 0.05 or less

Table 5 above describes significant value, t-test and coefficients of independent variables that indicate the relationship between independent and dependent variables.

Table 6

Summary result from regression model (employee's performance)

\begin{tabular}{lcccc}
\hline \multicolumn{1}{c}{ Code } & R square & Coefficient (Beta) & $\mathrm{t}$ & Sig \\
\hline PII23 & 0.404 & .232 & 2.347 & 0.020 \\
PII29 & 0.404 & .409 & 4.565 & 0.000 \\
PII8 & 0.205 & -.223 & -2.462 & 0.015 \\
PII2 & 0.205 & .324 & 3.472 & 0.001 \\
PII7 & 0.264 & .551 & 5.688 & 0.000 \\
PII11 & 0.264 & -.331 & -3.212 & 0.002 \\
PII10 & 0.275 &. .334 & -3.810 & 0.000 \\
PII14 & 0.275 & .407 & 4.444 & 0.000 \\
PII18 & 0.275 & -.441 & 2.500 & 0.014 \\
PII5 & 0.271 & .599 & -4.357 & 0.000 \\
PII30 & 0.271 & .329 & 7.185 & 0.000 \\
PII17 & 0.403 & .335 & 3.688 & 0.000 \\
PII25 & 0.403 & .400 & 3.775 & 0.000 \\
PII28 & 0.162 & & 4.493 & 0.000 \\
\hline
\end{tabular}

Note: Significance value of 0.05 or less 
Since the significance value is 0.05 or less, there are several non- significant coefficients, indicating that independent variables are not related with customer satisfaction. They are: Process control and improvement, Implementation, Continual evaluation. There are 11 variables that are significant. It means that the predictor CSF have relation with customer satisfaction. They are: preparation; planning; effective leader ship; recognition and reward; employee's attitude. Table 6 describes significant value, t-test and coefficients of independent variables that indicate the relationship between independent and dependent variables. Since the significance value is 0.05 or less, there are non-significant coefficients, indicating that critical success factors are not related with staff performance like implementation (employee's participation). There are 14 variables that are significant. It means that the predictor (critical success factors) have relation with staff performance. They are: preparation, process control \& improvement, planning, effective leadership, continual evaluation, recognition \& reward, employee's attitude.

Table 7

Summary result from regression model (Cost reduction)

\begin{tabular}{lcccc}
\hline Code & R square & Coefficients (Beta) & t & Sig \\
\hline PII29 & 0.207 & .249 & 2.412 & 0.017 \\
PII32 & 0.207 & .311 & 2.814 & 0.006 \\
PII8 & 0.040 & .203 & 2.044 & 0.043 \\
PII7 & 0.155 & .206 & 1.983 & 0.049 \\
PII11 & 0.155 & -.304 & -2.753 & 0.007 \\
PII22 & 0.155 & .310 & 3.183 & 0.002 \\
PII20 & 0.057 & .224 & 2.583 & 0.011 \\
PII18 & 0.260 & .358 & 3.649 & 0.000 \\
PII5 & 0.037 & -.247 & -2.128 & 0.035 \\
PII17 & 0.179 & .219 & 2.097 & 0.038 \\
PII25 & 0.179 & .270 & 2.597 & 0.010 \\
PII28 & 0.097 & .246 & 2.668 & 0.008 \\
\hline Note: Significance value of 0.05 or less & & &
\end{tabular}

Table 7 above describes significant value, t-test and coefficients of independent variables that indicate the relationship between independent and dependent variables. Since the significance value is 0.05 or less, there are significant coefficients, indicating that critical success factors are related with manufacturing cost reduction: They are: preparation, process control \& improvement, planning, implementation, effective leadership, continual evaluation, recognition \& reward, employee's attitude.

\subsubsection{Results of Hypothesis Testing}

Theoretical hypotheses are empirically tested. Independent variables with significant values less than 0.05 are accepted. The result is shown below.

H1: Providing comprehensive training and education to all levels of the company starting from front line workers to top managements will result in increased employee performance, customer satisfaction and decreasing manufacturing costs. This result is accepted. Since the significance value of the predictor training and education in comparison with employee performance, customer satisfaction and cost reduction are $0.00,0.00$ and 0.017 respectively. These results are less than the upper limit significant value of 0.05 .

H2: Having ownership towards the philosophy will result in increased employee performance, customer satisfaction and decreased manufacturing cost. This result is rejected. Since the significance value of the predictor ownership with employee performance, customer satisfaction and cost reduction are $0.647,0.504$ and 0.130 respectively. These results are greater than the upper limit significant value of 0.05 . 
H3: when employees working in team results in increased employee performance, customer satisfaction and decreased manufacturing cost. This result is rejected. Since the significance value of the predictor teamwork with employee performance, customer satisfaction and cost reduction are $0.972,0.296$, and 0.191 respectively. These results are greater than the upper limit significant value of 0.05 .

H4: Having effective vertical and horizontal communication in providing frame work of strategic improvement plan will result in increased employee performance, customer satisfaction and decreasing in manufacturing cost. This result is accepted. Since the significance value of the predictor planning or effective communication in comparison with employee performance, customer satisfaction and cost reduction are $0.02,0.01$ and 0.007 respectively. These results are less than the upper limit significant value of 0.05 .

H5: All levels of company employee's participation in the Kaizen implementation will result in increased employee performance, customer satisfaction and decreasing in manufacturing cost. This result is accepted only for comparison with cost reduction. Since the significance value of the predictor employee's participation in comparison with cost reduction is 0.011. But in comparison with employee performance and customer satisfaction, the significant value is 0.162 and 0.481 respectively. These results are greater than the upper limit significant value of 0.05 .

H6: Using process control and improvement techniques will result in increased employee performance, customer satisfaction and decreasing manufacturing cost. This result is accepted only for comparison with staff performance and cost reduction. Since the significance value of the predictor process control and improvement in comparison with employee performance and cost reduction is 0.01 and 0.043 respectively. But in comparison with customer satisfaction, the significant value is 0.812 . This result is greater than the upper limit significant value of 0.05 .

H7: Continual evaluation of the implementation and the performance of all levels of employees will result in increased employee performance, customer satisfaction and decreased manufacturing cost. This result is accepted only for comparison with employee performance and cost reduction. Since the significance value of the predictor continual evaluation in comparison with employee performance and cost reduction is 0.00 and 0.035 respectively. But in comparison with customer satisfaction, the significant value is 0.665 . This result is greater than the upper limit significant value of 0.05 .

H8: Establishing recognition and reward system in the company will result in increased employee performance, customer satisfaction and decreased manufacturing cost. This result is accepted. Since the significance value of the predictor recognition and reward in comparison with employee performance, customer satisfaction and cost reduction are $0.00,0.019$ and 0.01 respectively. These results are less than the upper limit significant value of 0.05 .

H9: Knowledgeable and committed effective Kaizen leadership will result in increased employee performance, customer satisfaction and decreased manufacturing cost. This result is accepted. Since the significance value of the predictor effective leadership in comparison with employee performance, customer satisfaction and cost reduction are $0.014,0.00$ and 0.00 respectively. These results are less than the upper limit significant value of 0.05 .

H10: Employee's attitude will result in increased employee performance, customer satisfaction and decreased manufacturing cost. This result is accepted. Since the significance value of the predictor employee's attitude in comparison with employee performance, customer satisfaction and cost reduction is $0.00,0.019$ and 0.008 respectively. These results are less than the upper limit significant value of 0.00 . These results are less than the upper limit significant value of 0.05.Based on this multiple regression analysis, the new developed model is shown as in Fig. 4. 
The above empirically tested model elaborates that even though the factorial analysis, as shown in the conceptual model, ownership and training \& education; teamwork and employee participation were independently 4 success factors, but, factorial analytical output merges them to 2 critical factor categories of preparation and implementation respectively as shown in Table 4. The multiple regression analysis output also shown that significant values of code items PII27, PII31, PII1, PII21, PII26, PII15, PII9, PII3, PII4, PII16, PII6 and PII13 are above the recommended 0.05 significant value. So, these items are rejected. Based on this, from 32 items only 20 items have high contribution for sustainable kaizen implementation in manufacturing industry, peacock. Besides to this, peacock should also focus on the 4 's of people, philosophy, process and problem solving to attain sustainable substantial improvements. In the conceptual model, there were 10 independent variables, after empirically testing these success factors were reduced to eight critical factors as shown in Fig. 3. Finally, the identified 8 critical factors in relation to their respective listed items have a big role on successful and sustainable kaizen implementation.

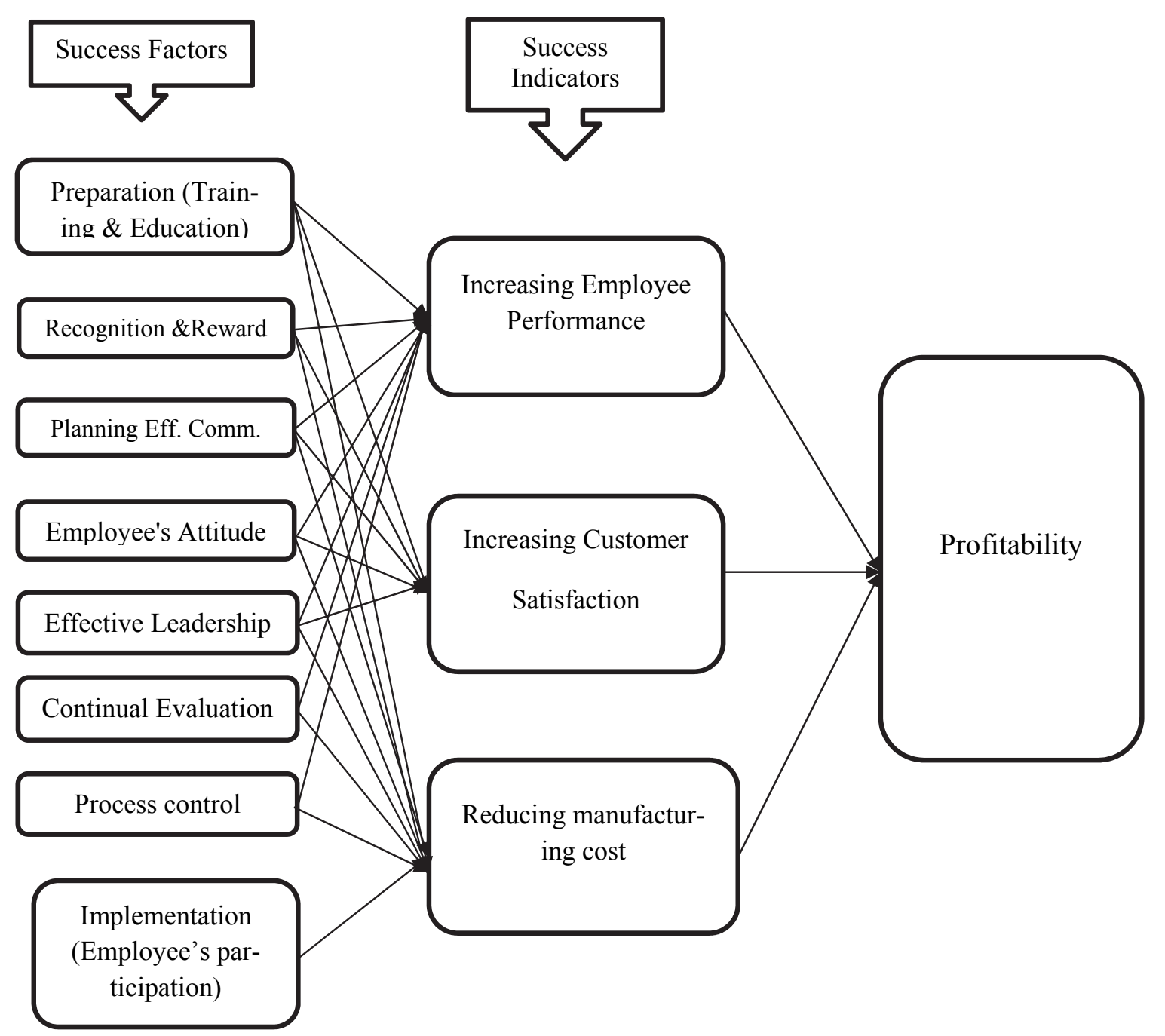

Fig. 4. New model developed after empirically tested

\section{Conclusion}

The following specific conclusions have been compiled from the surveys administered during the research process. The critical success factors for sustainable Kaizen implementation in Peacock shoes manufacturing industry are: Preparation - 16.056 \%, Process control - 10.286\%, Planning - 9.996\%, 
Implementation - 9.157\%, Effective leadership-8.525\%, Continual evaluation - 8.253\%, Recognition \& reward - 7.369\%, 8) Employee's attitude- 7.298\%. Preparation associated with education and training is key. This CSF is linked to people and related with employee performance, customer satisfaction and manufacturing cost. Process control is key. This factor is linked to process and related with employee performance and manufacturing cost. Planning associated with effective communication is key. This factor is linked to people and related with employee performance, customer satisfaction and manufacturing cost. Implementation associated with employee's participation is key. This factor is linked to problem solving and related with only manufacturing cost. Effective leadership on kaizen philosophy is key. This factor is linked to philosophy and people and related with employee performance, customer satisfaction and manufacturing cost. Continual evaluation is key. This factor is linked to process and related with staff performance and manufacturing cost. Recognition and reward is key. This factor is linked to people and related with employee performance, customer satisfaction and manufacturing cost. Employee's attitude is key. This factor is linked to people and related with employee performance, customer satisfaction and manufacturing cost. The peacock shoes manufacturing industry have, to an extent, made varying degrees of improvement with critical success factors. The researcher tried to show the hypothesis that is empirically tested. It indicates the identified 8 critical factors have high contribution on success indicators. The company top management should give focus on training and education during preparation time to develop employee's kaizen knowledge. The facilitators should control the process by applying improvement activities. There should be good planning that deploys to employees with effective horizontal and vertical communication. Peacock should implement kaizen activities with $100 \%$ employee's participation. The top management, facilitators and team leaders should have real leadership style in order to be role model and successfully completion of the implementation. There should be continual evaluation of activities on peacock by Ethiopian Kaizen Institute, Peacock Kaizen office and companies stakeholders like leather Industry Development Institute. The company should encourage best performer employees and teams by introducing recognition \& rewarding system continuously. The front line workers should also have positive attitude on implementing and accepting constructive feedbacks from their leaders. So, Peacock should implement 8 critical success factors and use the developed model for enabling sustainable kaizen implementation in order to achieve more qualitative, \& quantitative results and sustain these substantial improvements. Due to constraint of time, the research is limited to one company, and the study was undertaken in view of peacock shoes manufacturing industry. The identified critical factors and model developed also works only for the company. Other limitations include the absence of any local studies that shows the critical success factors for sustainable Kaizen implementation at the moment. Due to this fact the factors affecting for sustainable Kaizen implementation for successful completion of the research were taken from out of the country. For the future, the researcher will do on identifying and developing critical success factors model for selected textile, garment, leather, chemical, metal and agro processing industries in Ethiopia. At the end, the researcher believed that all findings on this research can be implemented in any shoe manufacturing industries in Ethiopia.

\section{Acknowledgments}

First of all, I would like to thank the Almighty GOD for giving me the inspiration to start and patience to finalize this article. Secondly, an article cannot be successfully done without the assistance, detractors, motivation and partnership of many individuals who have supported in different ways with the completion of the article. I would like to thank all those who have encouraged, enthused and abetted me in completing this article. Particularly, my deepest and heartfelt thanks to Dr. Kassu Jilcha assisstance professor and researcher for his unlimited support, creative suggestions, direction, advice, and patience with me during the preparation of this article. Last, but not least, I would like to thank my dearly loved wife for her darling, encouragement, patience and support throughout the preparation. 


\section{References}

Alaskari, O., Ahmad, M. M., Dhafr, N., \& Pinedo-Cuenca, R. (2013). Critical successful factors (CSFs) for successful implementation of lean tools and ERP systems.

Asedesach, A.(2014). A Thesis on Effects of kaizen Implementation, p. 41.

Bateman, N. (2005). Sustainability: the elusive element of process improvement. International Journal of Operations \& Production Management, 25(3), 261-276.

Bisgaard, S. (2007). Quality management and Juran's legacy. Quality and Reliability Engineering International, 23(6), 665-677.

Bisht, D. S. (2013). The Japanese Wow: Kaizen. VSRD International Journal of Business and Management Research, 167-172.

Blanche, M. T., Blanche, M. J. T., Durrheim, K., \& Painter, D. (Eds.). (2006). Research in practice: Applied methods for the social sciences. Juta and Company Ltd.

Boynton, A. C., \& Zmud, R. W. (1984). An assessment of critical success factors. Sloan management review, 25(4), 17-27.

Cooney, R., \& Sohal, A. (2004). Teamwork and total quality management: a durable partnership. Total Quality Management \& Business Excellence, 15(8), 1131-1142.

Farris, J.A. (2003). A standard frame work for sustaining Kaizen events. Master's Thesis, Department of Industrial and Manufacturing. Wichita, KS, USA.

García, J., Rivera, D., \& Iniesta, A. (2013). Critical success factors for Kaizen implementation in manufacturing industries in Mexico. International Journal of Advanced Manufacturing Technology, 68, $1-4$.

Jørgensen, F., Boer, H., \& Gertsen, F. (2004). Development of a team-based framework for conducting self-assessment of continuous improvement. Journal of Manufacturing Technology Management, 15(4), 343-349.

Landa, Am (2009). Critical success factors and permanence for Kaizen events. Sinnco, 1-20 (In Spanish).

Leidecker, J. K., \& Bruno, A. V. (1984). Identifying and using critical success factors. Long range planning, 17(1), 23-32.

Mfowabo, N. (2006). The impact of Total productive maintenance on manufacturing performance, 6(31), 5-14 (In Spanish).

Prajogo, D. I., \& Sohal, A. S. (2004). Transitioning from total quality management to total innovation management: an Australian case. International journal of quality \& reliability management, 21(8), 861-875.

Readman, J., \& Bessant, J. (2007). What challenges lie ahead for improvement programmes in the UK? Lessons from the CINet Continuous Improvement Survey 2003. International Journal of Technology Management, 37(3-4), 290-305.

Krejcie, R. V., \& Morgan, D. W. (1970). Determining sample size for research activities. Educational and psychological measurement, 30(3), 607-610.

Romero, R., Noriega, S., Escobar, C., \& Avila, D. (2009). Critical success factors: A competitiveness strategy. CULCYT, 6(31), 5-14.

Tapias A, Yeison A, Correa R \& Hernan J (2010). Kaizen: a case study. Redalyc, 16(45), 59-64 (In Spanish).

Vermaak, T. D. (2008). Critical success factors for the implementation of lean thinking in South African manufacturing organisations.

Vichea, S. (2005). Key Factors Affecting the Performance of foreign Direct Investment in Cambodia (Doctoral dissertation, a thesis submitted in partial fulfillment of Masters of Business Administrations, university of the Tai chamber of commerce). 


\section{Appendix}

The 32 items and respected code is presented as:

PII1: A salary promotion system to encourage employee participation in Kaizen

PII2: Standardization and designing "foolproof" implementation processes to minimize errors

PII3: Using idea generation soft techniques by following PDCA cycle extensively for process control and improvement

PII4: Well maintaining production equipment's according to the maintenance plan.

PII5: Regularly top management and relatives auditing the implementation

PII6: All employees recording Kaizen related data during implementation

PII7: Establish policy for Kaizen and cross functional goals realize through policy deployment and audits

PII8: Discussion of all employees Kaizen - related issues in meetings

PII9: Establishing evaluation systems to measure the performance of all employees

PII10: Focusing on bench marking activities for best practicing

PII1: Providing frame work of strategic improvement plan for achieving the objectives broadly defined by managements

PII12: Clarifying the organization's goals and objectives formulated

PII13: Working in team for fixing problems and scale up employee's capability

PII14: Top management's pledging to the development of the entire workforce and encourage participation, learning, innovation, and creativity throughout the organization to get shop floor commitment and employee trust

PII15: Aligning of short \& long term plans with a company's vision

PII16: Applying generated new ideas from employees for process modifications and change layouts

PII17: Financially rewarding for excellent suggestions to get shop floor commitment and employee trust

PII18: Testing the organization's mission and vision statements against the principles implicit in Kaizen PII19: Top managements participation in formation of realistic time scale for change and Kaizen organizational structure

PII20: The company implements various inspections effectively (incoming, process, and final products).

PII21: The company employees openness for accepting feedbacks

PII22: Organizing KPT from members of same disciplines

PII23: Views and understand Kaizen as a philosophy and a corporate strategy rather than another strategy 
PII24: Provide support and direction for Kaizen by allocating resources

PII25: Value employees as long term resources at all levels of the organization

PII26: Having positive attitude to actively involved employees in problem solving, quality \& productivity improvement

PII27: Change in organizational culture by build systems, procedures, and structures conducive to Kaizen

PII28: All employees of the willingness to accept the philosophy

PII29: Providing training and education for all personnel in Kaizen - related concepts and skills

PII30: Continually providing feedback to employees concerning the implementation

PII31: Maximizing ownership with management and employees commitment

PII32: Providing specific work-skills training to all employees

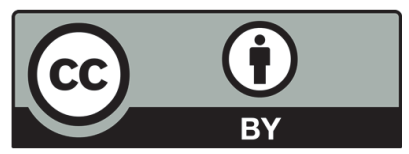

(C) 2017 by the authors; licensee Growing Science, Canada. This is an open access article distributed under the terms and conditions of the Creative Commons Attribution (CC-BY) license (http://creativecommons.org/licenses/by/4.0/). 